\title{
A STUDY ON PATTERN OF OCULAR TRAUMA AT A REGIONAL EYE HOSPITAL
}

\author{
K. S. Rajiv Krishna ${ }^{1}$
}

1Assistant Professor, Department of Ophthalmology, Andhra Medical College/ Government Regional Eye Hospital, Visakhapatnam, Andhra Pradesh, India.

\section{BACKGROUND}

Nowadays ocular injuries represent a sizeable number among cases attending Ophthalmic OPD and have been associated with long-term sequelae and reduced quality of life. Ocular trauma is an important public health hazard. Injury to the eye and its surrounding structures remain a leading cause of visual morbidity and blindness. Many ocular injuries are an avoidable cause of blindness and visual impairment.

The objective of the study is to evaluate the pattern of ocular injuries presenting at Regional Eye Hospital, Visakhapatnam, Andhra Pradesh.
\end{abstract}

ABSTRACT

\section{MATERIALS AND METHODS}

Patients attending routine OPD and Emergency Department of Government Regional Hospital, Visakhapatnam were taken into study. A total of 800 patients were analysed for various patterns of ocular trauma.

\section{RESULTS}

Ocular trauma accounted for approximately $0.83 \%$ of the total cases $(96,143)$ presenting to OPD and emergency departments at our institute. The period of study being from $01 / 06 / 2017$ to $31 / 05 / 2018$. RTA accounted for $28 \%$ of cases, $24 \%$ were occupation related and $16 \%$ of the cases were due to sports injuries. $40 \%$ of cases had adnexal injuries, $35 \%$ were closed globe injuries and $15 \%$ accounted for open globe injuries.

\section{CONCLUSION}

Ocular trauma is not only one of the common emergency conditions, but also frequently encountered in routine OPDs. People involved in physically active works like labourers, farmers and athletes are more prone for ocular trauma. Proper safety measures and health awareness can reduce the morbidity associated with ocular trauma.

\section{KEY WORDS}

Ocular Injury, Eye Emergency, Trauma, Epidemiology, Retrospective Studies.

HOW TO CITE THIS ARTICLE: Krishna KSR. A study on pattern of ocular trauma at a regional eye hospital. J. Evolution Med. Dent. Sci. 2018;7(36):4004-4007, DOI: 10.14260/jemds/2018/894

\section{BACKGROUND}

One of the main causes of severe ocular morbidity is ocular trauma. ${ }^{1}$ Globally, more than 55 million eye injuries occur per year, while there are approximately 1.6 million people with blindness from ocular trauma, 2.3 million people who are bilaterally visually impaired and 19 million people with unilateral blindness or visual loss. Uniocular or binocular loss or decrease of vision may result in significant economic burdens to families and governments due to time lost from work or school, and expensive hospitalisation, special treatment, prolonged follow-up and visual rehabilitation. ${ }^{2}$ It is likely that individuals of varying age, sex and environmental status are at different risks for ocular trauma; furthermore, injury severity may be associated with these and other factors. ${ }^{3}$ A thorough understanding of the factors contributing to ocular trauma is necessary if appropriate

'Financial or Other Competing Interest': None.

Submission 22-07-2018, Peer Review 17-08-2018,

Acceptance 24-08-2018, Published 30-08-2018.

Corresponding Author:

Dr. K. S. Rajiv Krishna,

2-45-14/1, GF101,

Veitla Park View Apartment,

MVP Colony, Sector-11,

Visakhapatnam-530017,

Andhra Pradesh, India.

E-mail: rajivkrishna9@yahoo.in

DOI: $10.14260 /$ jemds $/ 2018 / 894$ preventive and system-based policy is to be designed to address the issue of ocular injury. Morbidity related to ocular trauma is more prevalent in developing countries like India when compared with developed countries. ${ }^{4}$ Children, workers and farmers are more prone to ocular trauma for obvious reasons.

\section{Objectives of the Study}

The objective of this study is to evaluate the pattern of ocular trauma in the patients attending ophthalmic OPD and emergency section at Regional Eye Hospital, Visakhapatnam. This hospital is one of the main referral centres in north coastal Andhra Pradesh.

\section{MATERIALS AND METHODS}

We performed a retrospective descriptive study. A predesigned proforma was used to collect and tabulate the data. Data was analysed using MS Excel Software.

The period of this study is from 01/06/2017 to $31 / 05 / 2018 ; 800$ patients were included in the study. A detailed history is taken on the mode of the injury and type of trauma. History is taken directly from the patient and in children and unconscious patient's attendant history is noted. Thorough clinical examination was done with respect to general and ocular condition. Visual acuity, ocular movements, anterior segment, posterior segment, adnexal and orbital examination was done and entered in the proforma. Whenever required CT scan and MRI scan of the 
patients was ordered. Neurosurgery, Plastic Surgery, ENT specialist's opinion was taken wherever needed. Treatment was advised accordingly. Operational definitions were according to World Health Organization (WHO) and Birmingham Eye Trauma Terminology System (BETTS). ${ }^{5}$

\section{Blindness}

Visual acuity $<3 / 60$.

\section{Eye Wall}

Cornea and Sclera.

\section{Closed Globe Injury}

No Full Thickness Wound of the Eye Wall-

- Contusions: No full thickness wound, direct energy delivery (e.g. choroidal rupture) or due to change in shape of the globe (e.g. angle recession).

- Lamellar laceration: Partial thickness wound of the eye wall.

\section{Open Globe Injury}

\section{Full Thickness Wound of the Eye Wall-}

- Laceration: Full thickness wound at the impact site of a sharp object by outside- in mechanism.

- Penetrating: Entrance wound only.

- Perforating: Entrance plus exit wound.

- Intraocular Foreign Body: Technically, a penetrating injury, but grouped separately because of different clinical implications.

- Rupture: Full thickness wound by blunt object by insideout mechanism due to increased intraocular pressure.

\section{Adnexal Injuries}

Eyelid and/ or conjunctival injuries.

\section{RESULTS}

In this study, ocular trauma accounted for approximately $0.83 \%$ of the total cases $(96,143)$ presenting to OPD and emergency departments at our institute. The patients were grouped into four categories as shown in Fig. 1. Ocular trauma was found more common in $16-40$ (40\%) years' age group, probably related to more outdoor activity and risktaking jobs in that age group. $65 \%$ were males and $60 \%$ of the patients had rural background. Most common type is adnexal injuries involving lids or conjunctiva followed by closed globe injuries and open globe injuries. Among the closed globe injuries, extraocular foreign bodies $(60 \%)$ either on the cornea or in the fornices compelled the patients to consult the ophthalmologist. Penetrating injuries contributed to $50 \%$ of open globe injury cases. $30 \%$ of the cases presented to the emergency department. $65 \%$ of the cases presented immediately after the injury. RTA (28\%) and occupation related injuries (24\%) were more commonly noted in this study. Farmers and workers together were $50 \%$ of the patients by profession in this study. $82 \%$ of the cases were due to mechanical injuries. $65 \%$ of the patients presented early and $30 \%$ of the patients attended the emergency department. $32 \%$ of the patients were admitted and $68 \%$ of the patients were treated on an OPD basis. Some kind of surgical intervention was done in $26 \%$ of the cases. $20 \%$ of the cases in this study had associated injuries involving head, face or multiple organs. Anterior segment was involved in $66 \%$ of the cases.

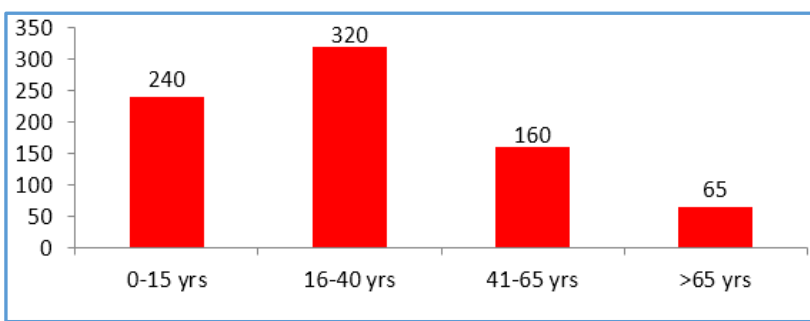

Figure 1. Age Wise Distribution

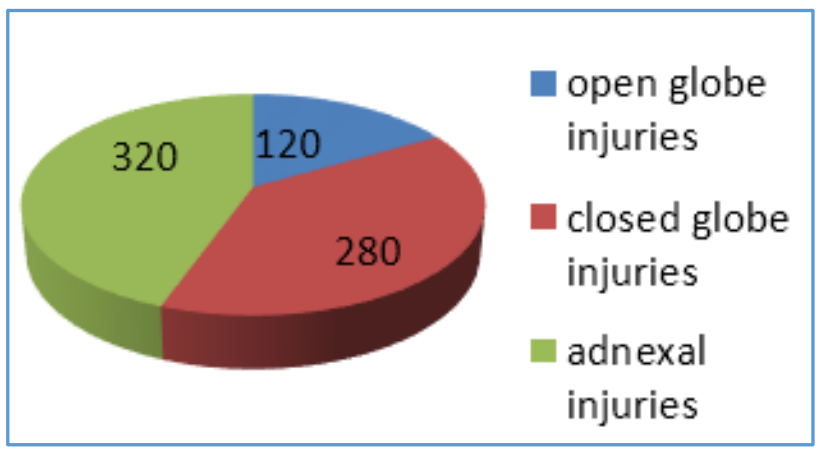

Figure 2. Types of Injuries

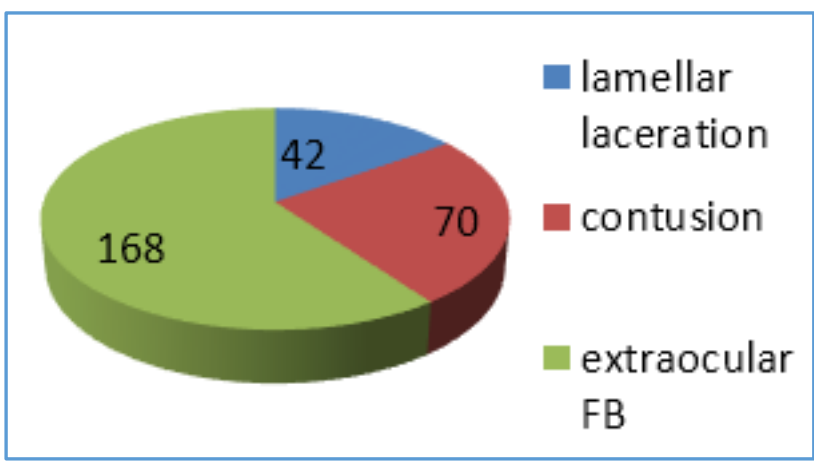

Figure 3. Types of Closed Globe Injuries

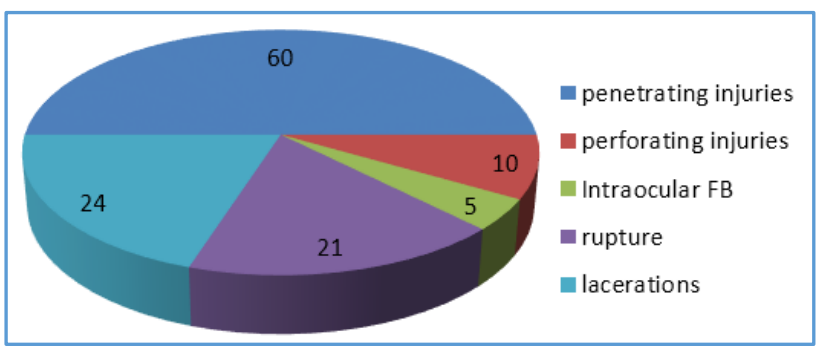

Figure 4. Graph showing types of Open Globe Injuries

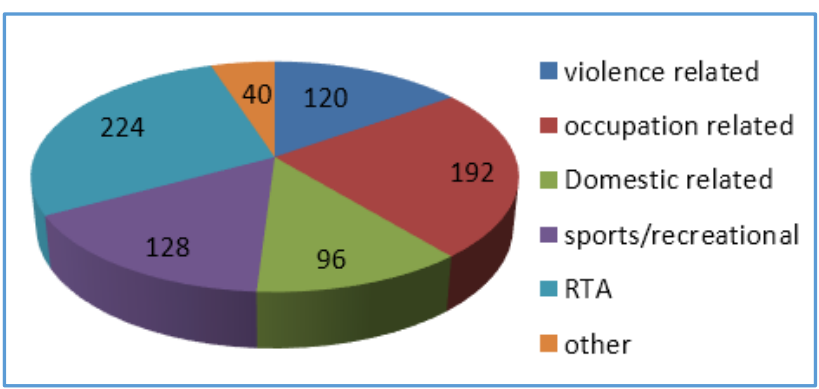

Figure 5. Graph showing various Situations leading to Ocular Trauma 


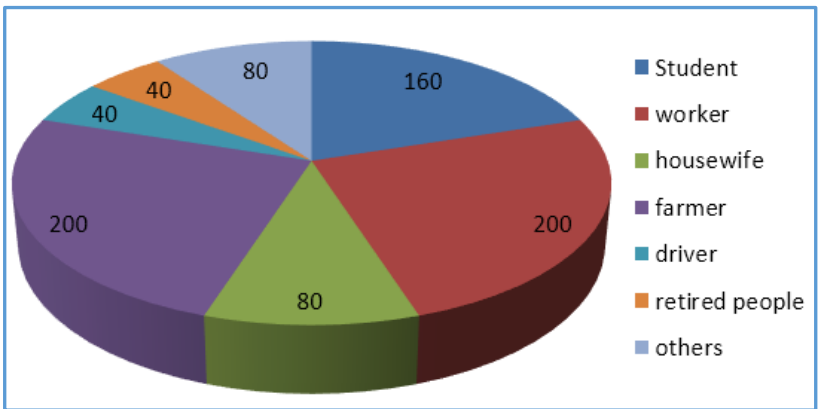

Figure 6. Graph showing Occupation of the subjects in the Study Group

\section{DISCUSSION}

Ocular trauma is an important cause of blindness and ocular morbidity. The common age for ocular trauma in this study was found to be 16 - 40 years. Voon et $\mathrm{al}^{6}$ and Aligolbandi et $\mathrm{al}^{7}$ in their respective studies reported a higher incidence in similar age groups. The magnitude of ocular trauma was found to be $0.83 \%$ out of total patients seen in our institute. Tityal et al 8 reported a prevalence of $1.03 \%$ in their study; Vats et $\mathrm{al}^{9}$ had a figure of $2.4 \%$ in their study in urban slums. Krishnaiah et al ${ }^{10}$ reported a prevalence of $10.6 \%$ in their study in rural south India. Direct comparison of this study with the data from some of the studies reviewed was difficult in some aspects due to different classification, definition and methods of reporting adapted in those studies.

In our study, male-to-female ratio was 1.85: 1 . Tityal et al in their study had high male-to-female ratio of 10: 1 and Aligolbandi et al in their study revealed a male-to-female ratio of 3: 1 . The higher incidence in males is most likely due to occupational hazards, ${ }^{11}$ more travel and violence. $65 \%$ of the patients in this study presented early within two days of injury, whereas Tityal et al in their study reported a figure of $74.5 \%$. More than three-fourth of the cases in our study presented with Uniocular involvement and remaining had ocular trauma in both the eyes.

RTA was the major cause of injury in our study (28\%). Voon et al and Xi Zhang et al in their studies noted work related trauma as the major cause, which accounted for $70 \%$ and $40.6 \%$ of cases respectively. $35 \%$ of the injuries were closed globe in nature and $15 \%$ were of open globe type in this study. Xi Zhang et al had $66 \%$ and $34 \%$ of open and closed globe injuries respectively in their series. Tityal et al in their study noted $45.4 \%$ of open globe injuries and $22.7 \%$ of closed globe injuries.

\section{CONCLUSION}

Ocular trauma leads to huge number of visits annually to an eye hospital. These injuries are differentially distributed across age and sex. Emergency treatment is required in all the cases in order to save vision and reduce morbidity. Inpatient admission depends on various factors like age, sex, season, ${ }^{12}$ mechanism of injury ${ }^{13}$ and medico-legal implications. Observations from this study may help in developing a policy aimed at preventing specific injury mechanisms among appropriate age groups. Health education and safety strategies should consider targeting at home level for the prevention of serious eye injuries in addition to the traditional work, sports and leisure environments and their related activities as domestic injuries are increasing day-byday. ${ }^{14}$ These types of studies emphasise the importance of wearing helmets and seatbelts while driving. Lot of sports related eye injuries and occupational hazards leading to ocular trauma can be prevented by using appropriate protective gear. Eye care programs should consider ocular trauma as a priority in rural population, 15 because the lifetime prevalence of ocular trauma is higher than that reported for glaucoma, age-related macular degeneration or diabetic retinopathy from this population. Further research is necessary to identify the potential viability and efficacy of interventions aimed at reducing incidence and severity of ocular trauma in our country. It is further recommended that government should design an urgent referral system ${ }^{16}$ for emergency care services for ocular trauma patients. Hospitals should improve their documentation system by designing a structured and standardised format to be used when clerking, treating and following up ocular trauma patients which will help in doing more research in the area, which in turn is fundamental in planning emergency eye care services.

\section{ACKNOWLEDGEMENTS}

I sincerely thank all faculty of the Institute for their help. Last but not the least, my gratitude to the patients and attendants with whom we personally interacted.

\section{REFERENCES}

[1] Negrel AD, Thylefors B. The global impact of eye injuries. Ophthalmic Epidemiology 1998;5(3):143-69.

[2] Teilsch JM, Parver LM. Determinants of hospital charges and length of stay for ocular trauma. Ophthalmology 1990;97(2):231-7.

[3] Parmar IPS, Nagpal RC, Sunandan S. Pattern of ocular injuries in Haryana. Ind J Ophthalmol 1985;33(3):1414.

[4] Zhang X, Liu Y, Ji X, et al. A retrospective study on clinical features and visual outcome of patients hospitalized for ocular trauma in Cangzhou, China. Article ID 7694913, Journal of Ophthalmology 2017;(2017): p. 6.

[5] Kuhn F, Morris R, Witherspoon CD, et al. Birmingham Eye Trauma Terminology system (BETT). Journal Français d'Ophthalmologie 2004;27(2):206-10.

[6] Voon LW, See J, Wong TY. The epidemiology of ocular trauma in Singapore: perspective from the emergency service of a large tertiary hospital. Eye Lond 2001;15(Pt 1):75-81.

[7] Balaghafari A, Siamian H, Aligolbandi K. Ocular trauma: 2 years retrospective study in Sari, Iran. Materia Socio-Medica 2013;25(4):230-2.

[8] Tityal GS, Prakash C, Gupta S, et al. Pattern of ocular trauma in tertiary care hospital of Kumaon region, Uttarakhand. J Indian Acad Forensic Med 2013;35(2):116-9.

[9] Vats S, Murthy GVS, Chandra M, et al. Epidemiological study of ocular trauma in an urban slum population in Delhi, India. Indian Journal of Ophthalmology 2008;56(4):313-6.

[10] Krishnaiah S, Nirmalan PK, Shamanna BR, et al. Ocular trauma in a rural population of Southern India: the Andhra Pradesh Eye Disease Study. Ophthalmology 2006;113(7):1159-64. 
[11] Shashikala P, Sadiqulla M, Shivakumar D, et al. Profile of ocular trauma in industries-related hospital. Indian Journal of Occupational and Environmental Medicine 2013;17(2):66-70.

[12] Ramirez DA, Porco TC, Lietman TM, et al. Ocular injury in United States Emergency Departments: seasonality and annual trends estimated from a nationally representative dataset. American Journal of Ophthalmology 2018;191:149-55.

[13] Haring RS, Canner JK, Haider AH, et al. Ocular injury in the United States: Emergency Department visits from 2006-2011. Injury 2016;47(1):104-8.
[14] Desai P, MacEwen CJ, Baines P, et al. Incidence of cases of ocular trauma admitted to hospital and incidence of blinding outcome. The British Journal of Ophthalmology 1996;80(7):592-6.

[15] Nirmalan PK, Katz J, Tielsch JM, et al. Ocular trauma in a rural south Indian population: the Aravind Comprehensive Eye Study. Ophthalmology 2004;111(9):1778-81.

[16] Ross M, El-Haddad C, Deschenes J. Ocular injury in orbital fractures at a level I trauma center. Canadian Journal of Ophthalmology 2017;52(5):499-502. 